\title{
The Gap between Urban and Rural Development Levels Narrowed
}

\author{
Mou Wang, ${ }^{1,2}$ Wenmei Kang, ${ }^{3}$ and Ruiying Zhang $\mathbb{D}^{4}$ \\ ${ }^{1}$ Research Institute for Eco-Civilization (RIEco), Chinese Academy of Social Sciences (CASS), Beijing, China \\ ${ }^{2}$ Research Centre for Sustainable Development, Chinese Academy of Social Sciences (CASS), Beijing, China \\ ${ }^{3}$ University of Chinese Academy of Social Sciences, Beijing, China \\ ${ }^{4}$ Tianjin Agriculture University, Tianjin, China \\ Correspondence should be addressed to Ruiying Zhang; zry8063@163.com
}

Received 29 April 2020; Revised 26 August 2020; Accepted 10 September 2020; Published 28 September 2020

Academic Editor: Jianhong (Cecilia) Xia

Copyright (c) 2020 Mou Wang et al. This is an open access article distributed under the Creative Commons Attribution License, which permits unrestricted use, distribution, and reproduction in any medium, provided the original work is properly cited.

\begin{abstract}
The difference between urban and rural development levels (URDL) and the deficiency of rural development level have become the weak points for China to achieve balanced and high-quality development. In order to reveal the changing trend of urban-rural differences in China over the years and provide a reference for the policy-making of the balanced development of urban and rural areas and high-quality economic development, this paper uses the United Nations Development Program-adjusted Human Development Index (HDI) calculation method to calculate the urban and rural areas, based on 1995-2017 national time series data and provincial panel data. On this basis, this paper uses the Logarithmic Mean Weight Divisia to decompose the dynamic changes of the difference of URDL and analyzes the spatial equilibrium of the change trend of the differences of URDL, supplementing the shortcomings of the existing literature which only focuses on income, education, and other local areas and lacks continuity and comparison. The research finds that 1 . based on the time series analysis of the difference of URDL, this paper firstly proposes the "inverted U" curve for the difference of URDL in China, which shows that the difference of URDL in China has experienced a process from expansion (1995-2001) to high fluctuation (2001-2011) to continuous convergence (2011-2017). 2. From the factor decomposition effect of the difference of URDL, the difference expansion period is caused by the increase in the gap between the Health Index, the Education Index, and the Income Index. With the decline in the gap between education levels and life expectancy, the growth trend of China's urban-rural gap has been suppressed, and it has entered a high platform period with relative small fluctuation. After 2011, benefiting from the large decline in income level gaps, China's urban-rural difference has entered a period of convergence. 3. From the perspective of the spatial evolution characteristics of the gap of URDL, the overall coefficient of variation of the country has shown a downward trend. The degree of spatial equilibrium is gradually increasing, and the overall changes in the east, west, and northeast are the same as the overall trend of the country. The decline in the northeast is the largest, the west is the second, and the east is the least. The middle shows a slight upward trend, but the value of each year is always smaller compared with other regions. Generally speaking, the gap of URDL is relatively good in the middle and northeast, followed by the east, and there is still much room for improvement in the balance of the west.
\end{abstract}

\section{Introduction and Literature Review}

As a developing country, China's urban and rural development has typical dual-structural characteristics. The countryside has made great contributions in the process of China's economic development, but the differences between urban and rural development levels and insufficient rural development levels have become the shortcomings of China's balanced and high-quality development. From the report of the 16th National Congress of 2002 on "coordinating urban and rural economic and social development" to the report of the 17th National Congress of 2007 on "urban and rural integration" to the 2013 Third Plenary Session of the 18th Central Committee of the People's Republic of China on the issue of "new urban-rural relations" and the report of the 19th National Congress of 2017 on "urban-rural integration development", the emphasis on the imbalance between urban and rural development has been increasing. Revealing the gap between urban and rural development and analyzing the causes of development 
differences not only allow us to clearly understand the changing trends of urban and rural development differences but also provide a reference for balanced urban and rural development and policy-making of economic high-quality development.

Urban-rural difference is an important area for studying the economic and social development of developing countries. Generally speaking, the research on urban-rural differences includes two areas, one is to comprehensively and holistically analyze the urban-rural differences, and the other is to conduct research on urban-rural differences in a certain area such as education and income.

In terms of comprehensive and holistic analysis, the published literature mainly conducts research from qualitative and quantitative methods. The qualitative research method mainly uses qualitative analysis with multielement description and combines with the empirical judgment of researchers. For example, Wang and He studied the gap between urban and rural development from 1978 to 2003 [1], Guo studied the gap between urban and rural areas before 2003 [2], and Zhong et al. and others studied the urban-rural gap before 2007 [3]. It is relatively consistent that almost all of the qualitative research papers [1-11] that study the gap between urban and rural areas believe that with the economic development, the gap between urban and rural areas in China is expanding. There are not many papers on quantitative research on the overall gap between urban and rural development in China. Song and Ma used the Human Development Index to measure the urban-rural gap between 1990 and 2002 in China and found that the gap between urban and rural areas in China has been expanding from 1990 to 2002 [12]. In addition to domestic research results, some international research reports and papers can also provide methodology and conclusion references for the study of urban-rural gap. For example, the Mongolian Human Development Report shows that the gap between urban and rural areas has expanded from 1999 to 2002, from 0.067 in 1999 to 0.087 in 2002 [13]; the gap between the urban and rural Human Development Index in Assam, India, in 2001 was 0.021 [14]; the urban and rural Gini coefficients in Colombia and Peru are shrinking [15].

The research results on the urban-rural gap in a specific field are much richer than the overall urban-rural gap. From the published literature [16-45], studies on urban-rural gap mainly include education, income, social security, consumption, and wage. These studies mostly use quantitative research methods such as direct ratio or difference between urban and rural factors $[17,18,20-22,26,29,38,40,42]$, the Gini coefficient [19], coefficient of variation [23], and Theil Index [24]. Due to the wide differences in development levels, speeds, and priority development degree in different periods, it is difficult to judge the differences between urban and rural development levels in other fields or the overall differences in urban and rural development levels. From the existing literature, such as educational opportunities (1940-2010) [16], income gap (2003-2017) [17, 18], income inequality (1978-2005) [19], absolute gap in consumption levels (2000-2015) [20], income ratio (1985-2012) [21], and wage gap (1988-2008) [22] are constantly expanding, income ratio (2013-2017) [18], relative gap in consumption levels (2000-2015) [20], information infrastructure conditions of primary and secondary schools, and information technology teacher resource allocation (2006-2016) [23] are in narrowing trends, and some studies have found that after two "V" or "W" shaped changes, the urban-rural income gap in China has begun to enter a continuous decline in 2009 [24], the urban-rural income gap showed a U-shaped pattern of decline followed by rise during 1978-2008 economic development [25], the urban-rural income ratio and consumption ratio showed a " $M$ " shaped change during 1952-2017 [26], and the urban-rural income gap has gone through the process of equalization-expansion-narrowingexpansion-narrowing-relaxing since the founding of People's Republic of China [27].

To sum up, although China has accumulated some research results on the issue of urban-rural gap, the overall trend of urban-rural development differences is not clear. Concerning the research on the differences between urban and rural areas in specific fields such as income and education, the conclusions are highly fragmented due to the differences in the fields. It can only be concluded that the trend of changes in the specific field but cannot be used to infer the overall trend of urban and rural differences; while for comprehensive and holistic research, the number of papers is very limited, and the continuity of the research is relatively lacking. For example, Song and Ma [12] used the Human Development Index to conduct research. However, there has been no relevant literature for follow-up and comparative studies since 2002, which cannot reveal the longer-term period, especially the current trend. In comprehensive and holistic research, studies that judge the differences between urban and rural development through qualitative descriptions are difficult to obtain consensus due to the differences in researchers' knowledge background and research experience, and the continuity and comparability of the research are also relatively weak. In order to better understand the changing trend of China's urban-rural relations, and analyze and determine the future and long-term changes, this paper will use the United Nations Development Program (UNDP)-adjusted Human Development Index calculation method widely recognized by the international community to analyze and calculate the national time serial data from 1995 to 2017 and the panel data of each province, and reveal the overall trend of China's urban-rural development differences, analyze the driving factors of urban-rural development differences, and provide basic reference information for a comprehensive understanding and analysis of China's urban-rural development and change trends.

\section{Data and Methodology}

2.1. The Difference between the Urban and Rural HDI. Based on the UNDP's adjustment of the subindex and weighting method of the Human Development Index in 2010, the available data in this paper are used to calculate the difference between the urban and rural Human Development Index in China according to the latest index system 
measurement method (formula (1)). The calculation method (due to the lack of statistics on the expected education of urban and rural areas, the Education Index in the Human
Development Index only includes the average years of education) is as follows:

$$
\begin{aligned}
H D I_{i} & =\left(L E I_{i} * E I_{i} * I I_{i}\right)^{1 / 3}=\left\{\left[\frac{\left(E L_{i}-E L_{\min }\right)}{\left(E L_{\max }-E L_{\min }\right)}\right] *\left[\frac{\left(A E Y_{i}-A E Y_{\min }\right)}{\left(A E Y_{\max }-A E Y_{\min }\right)}\right] *\left[\frac{\left(L N\left(P G N I_{i}\right)-L N\left(P G N I_{\text {min }}\right)\right)}{\left(L N\left(P G N I_{\max }\right)-L N\left(P G N I_{\min }\right)\right.}\right]\right\}^{1 / 3} \\
& =\left\{\left[\frac{\left(E L_{i}-E L_{\min }\right)}{\left(E L_{\max }-E L_{\min }\right)}\right] *\left[\frac{\left(P P R_{i} * 6+J P R_{i} * 9+S P R_{i} * 12+A C P R_{i} * 16-A E Y_{\min }\right)}{\left(A E Y_{\max }-A E Y_{\min }\right)}\right]\right. \\
& \left.*\left[\frac{\left(L N\left(P G N I_{i}\right)-L N\left(P G N I_{\min }\right)\right)}{\left(L N\left(P G N I_{\max }\right)-L N\left(P G N I_{\min }\right)\right]}\right]\right\}^{1 / 3} .
\end{aligned}
$$

In formula (1), $H D I_{i}$ is the Human Development Index in year $i, L E I_{i}$ is the Health Index in year $i, E I_{i}$ is the Education Index in year $i, I I_{i}$ is the Income Index in year $i, E L_{i}$ is the life expectancy in year $i, E L_{\min }$ is the minimum life expectancy, $E L_{\max }$ is the maximum expected life expectancy, $P G N I_{i}$ is the per capita GNI (2011, PPP \$) in year $i, P G N I_{\text {min }}$ is the minimum per capita income, $P G N I_{\max }$ is the maximum per capita income, $A E Y_{i}$ is the average years of education in year $i, A E Y_{\min }$ is the minimum value of average years of education, $A E Y_{\max }$ is the maximum value of average years of education, $P P R_{i}$ is the proportion of the primary school population in year $i, J P R_{i}$ is the proportion of junior high school population in year $i, S P R_{i}$ is the proportion of high school population in year $i$, and $A C P R_{i}$ is the proportion of population of university and above in year $i$. Among them, $E L_{\min }, E L_{\max }, P G N I_{\min }, P G N I_{\max }, A E Y_{\min }$, and $A E Y_{\max }$ are shown in Table 1. The remaining data sources and processing methods in the HDI calculation formula are as follows.

The calculation data sources and processing methods are as follows:

(1) Sources and processing methods of per capita income data: the HDI methodology uses the US dollar GNI index measured in purchasing power parity (PPP) in 2011, and China's GDP statistics cannot be directly substituted into the calculation. This paper uses the ratio of per capita GDP data measured in RMB prices of the year based on the China Statistical Yearbook to GNI data measured in 2011 PPP prices to obtain a conversion factor. Based on this conversion factor, the national and local GNI data measured in 2011 PPP prices are calculated.

(2) Sources and processing methods of life expectancy data: the national urban and rural life expectancy data only contain the year 2000's statistical data, so this paper quotes urban and rural life expectancy data from 1995 to 2000, 2005, and 2009 in published papers $[12,46]$. From the year 2000 to 2005 and year
2005 to 2009, urban and rural life expectancies were obtained by interpolation, and from the year 2010 to 2017, urban and rural life expectancies were obtained by extrapolation from the average annual growth rate from 2000 to 2009. At present, the life expectancy data for urban and rural areas in 31 provinces in the country are only for the year 2000. Therefore, this paper uses the binary regression method to analyze the life expectancy and per capita disposable income of urban and rural areas from 1995 to 2017 and calculate the life expectancy for urban and rural areas in 31 provinces. And this paper adjusts the estimated data matrix with statistics for 31 provinces in the year 2000 .

(3) Data sources and processing methods of average years of education: relevant data of average years of education in China are calculated according to cities, towns, and counties. There are no statistical data on the urban and rural level. Therefore, in this paper, referring to the urban and rural classification method of the National Bureau of Statistics, the data of cities and towns are combined as the urban data and counties as rural data (reference URL: http://www. stats.gov.cn/tjzs/cjwtjd/201308/t20130829_74318. html. In the data related to the Education Index, the county is similar to rural and the city and town are similar to urban).

(4) The determination of starting year of the data column: in 2010, UNDP adjusted the methodology of the Human Development Index to replace the previous adult literacy rate and comprehensive gross enrollment rate with the average years of education and expected years of education. Statistics on the average years of education in China began in 1995. Therefore, the urban and rural Human Development Index of the country and provinces has been measured since 1995.

Based on the above methods, the calculation formula for the difference between urban and rural development levels is 
TABLe 1: Human Development Index related indicators for maximum and minimum criteria.

\begin{tabular}{lcc}
\hline Indicator & Max & Min \\
\hline Life expectancy & 85 & 20 \\
Average years of education & 15 & 0 \\
Expected years of education & 18 & 0 \\
Per capita income $(2011$, PPP $\$)$ & 75000 & 100 \\
\hline
\end{tabular}

Data sources: UNDP official website, http://hdr.undp.org/sites/default/files/hdr2016_technical_notes.pdf.

$$
\begin{aligned}
M_{i}= & H D I_{i}^{U}-H D I_{i}^{R}=\left\{\left[\frac{\left(E L_{i}^{U}-E L_{\min }\right)}{\left(E L_{\max }-E L_{\min }\right)} *\left[\frac{\left(P P R_{i}^{U} * 6+J P R_{i}^{U} * 9+S P R_{i}^{U} * 12+A C P R_{i}^{U} * 16-A E Y_{\text {min }}\right)}{\left(A E Y_{\max }-A E Y_{\text {min }}\right)}\right]\right.\right. \\
& \left.\left.*\left[\frac{\left(L N\left(P G N I_{i}^{U}\right)-L N\left(P G N I_{\min }\right)\right)}{\left(L N\left(P G N I_{\max }\right)-L N\left(P G N I_{\min }\right)\right)}\right]\right]\right\}^{1 / 3} \\
& -\left\{\left[\frac{\left(E L_{i}^{R}-E L_{\min }\right)}{\left(E L_{\max }-E L_{\min }\right)} *\left[\frac{\left(P P R_{i}^{R} * 6+J P R_{i}^{R} * 9+S P R_{i}^{R} * 12+A C P R_{i}^{R} * 16-A E Y_{\text {min }}\right)}{\left(A E Y_{\max }-A E Y_{\min }\right)}\right]\right.\right. \\
& \left.\left.*\left[\frac{\left(L N\left(P G N I_{i}^{R}\right)-L N\left(P G N I_{\min }\right)\right)}{\left(L N\left(P G N I_{\max }\right)-L N\left(P G N I_{\min }\right)\right)}\right]\right]\right\}^{1 / 3} .
\end{aligned}
$$

2.2. Logarithmic Mean Divisia Index. Logarithmic Mean Divisia Index (here after referred to as LMDI) is a more commonly used research method to analyze different variables based on the magnitude and the change of influence. This paper uses LMDI to decompose the changes in the Human Development Index differences across the country and provinces and explores the main reasons affecting the changes in the Human Development Index from the aspects of Health Index effect, Income Index effect, and Education Index effect.

Logarithmic formula (1) gives

$$
\begin{aligned}
& \operatorname{Ln}\left(H D I_{i}^{U}\right)=\frac{1}{3} \operatorname{Ln}\left(\operatorname{LEI}_{i}^{U}\right)+\frac{1}{3} \operatorname{Ln}\left(E I_{i}^{U}\right)+\frac{1}{3} \operatorname{Ln}\left(I I_{i}^{U}\right), \\
& \operatorname{Ln}\left(H D I_{i}^{R}\right)=\frac{1}{3} \operatorname{Ln}\left(L E I_{i}^{R}\right)+\frac{1}{3} \operatorname{Ln}\left(E I_{i}^{R}\right)+\frac{1}{3} \operatorname{Ln}\left(I I_{i}^{R}\right) .
\end{aligned}
$$

Let the change in the difference between the urban and rural Human Development Index from the national $T-j$ period to the $T$ period be $\Delta M$, then

$$
\begin{aligned}
& \Delta M=M_{T}-\mathrm{M}_{\mathrm{T}-\mathrm{j}}=\left(\mathrm{HDI}_{\mathrm{T}}^{\mathrm{U}}-\mathrm{HDI}_{\mathrm{T}}^{\mathrm{R}}\right)-\left(\mathrm{HDI}_{\mathrm{T}-\mathrm{j}}^{\mathrm{U}}-\mathrm{H} \mathrm{DI}_{\mathrm{T}-\mathrm{j}}^{\mathrm{R}}\right)=\left(\mathrm{HDI}_{\mathrm{T}}^{\mathrm{U}}-\mathrm{HDI}_{\mathrm{T}-\mathrm{j}}^{\mathrm{U}}\right)-\left(\mathrm{H} \mathrm{DI}_{\mathrm{T}}^{\mathrm{R}}-\mathrm{HDI}_{\mathrm{T}-\mathrm{j}}^{\mathrm{R}}\right) \\
& =\left(\operatorname{Ln}\left(H D I_{T}^{U}\right)-\operatorname{Ln}\left(\mathrm{HDI}_{\mathrm{T}-\mathrm{j}}^{\mathrm{U}}\right)\right) * \frac{H D I_{T}^{U}-H D I_{T-j}^{U}}{\left(\operatorname{Ln}\left(H D I_{T}^{U}\right)-\mathrm{Ln}\left(\mathrm{HDI}_{\mathrm{T}-\mathrm{j}}^{\mathrm{U}}\right)\right)}-\left(\operatorname{Ln}\left(H D I_{T}^{R}\right)-\mathrm{Ln}\left(\mathrm{H} \mathrm{DI}_{\mathrm{T}-\mathrm{j}}^{\mathrm{R}}\right)\right) * \frac{H D I_{T}^{R}-H D I_{T-j}^{R}}{\left(\operatorname{Ln}\left(H D I_{T}^{R}\right)-\mathrm{Ln}^{\mathrm{N}}\left(\mathrm{HDI}_{\mathrm{T}-\mathrm{j}}^{\mathrm{R}}\right)\right)} \\
& =\left(\left(\frac{1}{3} \operatorname{Ln}\left(L E I_{T}^{U}\right)+\frac{1}{3} \operatorname{Ln}\left(E I_{T}^{U}\right)+\frac{1}{3} \operatorname{Ln}\left(I I_{T}^{U}\right)\right)-\left(\frac{1}{3} \operatorname{Ln}\left(L E I_{T-j}^{U}\right)+\frac{1}{3} \operatorname{Ln}\left(E I_{T-j}^{U}\right)+\frac{1}{3} \operatorname{Ln}\left(I I_{T-j}^{U}\right)\right)\right) * \frac{H D I_{T}^{U}-H D I_{T-j}^{U}}{\left(\operatorname{Ln}\left(H D I_{T}^{U}\right)-\mathrm{Ln}\left(\mathrm{H} \mathrm{DI}_{\mathrm{T}-\mathrm{j}}^{\mathrm{U}}\right)\right)} \\
& -\left(\left(\frac{1}{3} \operatorname{Ln}\left(L E I_{T}^{R}\right)+\frac{1}{3} \operatorname{Ln}\left(E I_{T}^{R}\right)+\frac{1}{3} \operatorname{Ln}\left(I I_{T}^{R}\right)\right)-\left(\frac{1}{3} \operatorname{Ln}\left(L E I_{T-j}^{R}\right)+\frac{1}{3} \operatorname{Ln}\left(E I_{T-j}^{R}\right)+\frac{1}{3} \operatorname{Ln}\left(I I_{T-j}^{R}\right)\right)\right) * \frac{H D I_{T}^{R}-H D I_{T-j}^{R}}{\left(\operatorname{Ln}\left(H D I_{T}^{R}\right)-\mathrm{Ln}^{2}\left(\mathrm{HDI}_{\mathrm{T}-\mathrm{j}}^{\mathrm{R}}\right)\right)} \\
& =\frac{1}{3}\left(\operatorname{Ln}\left(\frac{L E I_{T}^{U}}{L E I_{T-j}^{U}}\right) * \frac{H D I_{T}^{U}-H D I_{T-j}^{U}}{\left(\operatorname{Ln}\left(H D I_{T}^{U}\right)-\operatorname{Ln}\left(\mathrm{HDI}_{\mathrm{T}-\mathrm{j}}^{\mathrm{U}}\right)\right)}-\operatorname{Ln}\left(\frac{L E I_{T}^{R}}{L E I_{T-j}^{R}}\right) * \frac{H D I_{T}^{R}-H D I_{T-j}^{R}}{\left(\operatorname{Ln}\left(H D I_{T}^{R}\right)-\mathrm{Ln}\left(\mathrm{HDI}_{\mathrm{T}-\mathrm{j}}^{\mathrm{R}}\right)\right)}\right) \\
& +\frac{1}{3}\left(\operatorname{Ln}\left(\frac{E I_{T}^{U}}{E I_{T-j}^{U}}\right) * \frac{H D I_{T}^{U}-H D I_{T-j}^{U}}{\left(\operatorname{Ln}\left(H D I_{T}^{U}\right)-\operatorname{Ln}\left(\mathrm{HDI}_{\mathrm{T}-\mathrm{j}}^{\mathrm{U}}\right)\right)}-\operatorname{Ln}\left(\frac{E I_{T}^{R}}{E I_{T-j}^{R}}\right) * \frac{H D I_{T}^{R}-H D I_{T-j}^{R}}{\left(\operatorname{Ln}\left(H D I_{T}^{R}\right)-\operatorname{Ln}\left(\mathrm{HDI}_{\mathrm{T}-\mathrm{j}}^{\mathrm{R}}\right)\right)}\right) \\
& +\frac{1}{3}\left(\operatorname{Ln}\left(\frac{I I_{T}^{U}}{I I_{T-j}^{U}}\right) * \frac{H D I_{T}^{U}-H D I_{T-j}^{U}}{\left(\operatorname{Ln}\left(H D I_{T}^{U}\right)-\operatorname{Ln}\left(\mathrm{HDI}_{\mathrm{T}-\mathrm{j}}^{\mathrm{U}}\right)\right)}-\operatorname{Ln}\left(\frac{I I_{T}^{R}}{I I_{T-j}^{R}}\right) * \frac{H D I_{T}^{R}-H D I_{T-j}^{R}}{\left(\operatorname{Ln}\left(H D I_{T}^{R}\right)-\operatorname{Ln}\left(\mathrm{HDI}_{\mathrm{T}-\mathrm{j}}^{\mathrm{R}}\right)\right)}\right)=\Delta L E I+\Delta E I+\Delta I I .
\end{aligned}
$$


In formula (4), $\Delta L E I, \Delta E I$, and $\Delta I I$ represent the changes in the urban-rural differences of the country's Health Index, Income Index, and Education Index during the period $T-j \sim T$, respectively.

2.3. Coefficient of Variation. China has a vast territory, there are differences in resource endowments and natural conditions in different provinces, and there are also significant differences in economic and social development, resulting in spatial equilibrium differences in urban and rural human development levels across the country and in various regions. The calculation methods that reflect the spatial equilibrium development mainly include Gini coefficient, Theil Index, coefficient of variation, etc. This paper uses the coefficient of variation to measure the magnitude and trend of the gap between urban and rural human development across the country and regions according to the availability of data and research demand, and explain the spatial equilibrium of the gap between urban and rural development levels across the country and regions. The regional division is based on the commonly used 10:6: 11:3 classification standard in the national statistics (Table 2)(there are 30 provinces in total due to the difficulty of data acquisition in Tibet), which divides all provinces in China into four regions: east, middle, west, and northeast.

The calculation method based on the gap between urban and rural human development to reflect the spatial equilibrium development is as follows:

$$
C V_{i}=\frac{\sqrt{\sum_{j=1}^{m}\left(M_{i j}-M_{i}\right)^{2} / m}}{M_{i}} .
$$

In formula (5), $C V_{i}$ represents the coefficient of variation of the gap between urban and rural human development levels in national, eastern, central, western, and northeastern countries in year i. $M_{i}$ represents the gap in human development in national urban and rural areas in year $i$, and $M_{i j}$ represents the gap in human development level between urban and rural areas in province $j$ in year $i . m$ represents the number of provinces included in each region.

\section{Findings}

3.1. The Trend of Human Development Level Difference between Urban and Rural Areas. From 1995 to 2017, the differences of human development levels between urban and rural areas in China showed an "inverted U-shaped" structure, which can be roughly divided into three stages (Table 3 and Figure 1): (1) the period of difference expansion from 1995 to 2001. The difference in human development between urban and rural areas increased from 0.129 to 0.140 with an average annual growth rate of $1.4 \%$. During this period, the urban-rural difference continued to expand; (2) the period of difference high fluctuations between 2001 and 2011 where the difference in human development between urban and rural areas is adjusted around 0.140 with fluctuations; (3) the period of difference convergence between
2011 and 2017. The difference of human development levels between urban and rural areas has been reduced from 0.139 to 0.135 with an average annual decrease of $0.5 \%$, indicating that China's urban-rural differences are declining.

Analysis are based from the perspective of the factors that affect the future change trends in urban and rural human development levels. First, in terms of income level differences, the per capita disposable income ratio of urban and rural residents in China has shown a linear decline after reaching its peak in 2003 (the ratio of per capita disposable income of urban and rural residents calculated according to the China Statistical Yearbook). With China's balanced development and the implementation of poverty alleviation policies, the downward trend is expected to be consolidated. Secondly, in terms of the differences in health levels, the Health Index of Chinese cities and towns in 2017 has reached 0.910, which is slightly lower than that of the United States (0.916) and at a higher level. With the popularization of rural basic medical facilities and the increase of new rural cooperative medical insurance rate of farmers, the life expectancy in rural areas will also increase, and the difference in life expectancy between urban and rural areas is expected to narrow. Third, in terms of educational level differences, the advancement of policies and measurements such as urban-rural integration and urbanrural education balance provide guarantees for narrowing the gap between urban and rural education levels. Based on the trend analysis of the above three influencing factors, it is carefully determined that China's future urban and rural human development level differences will continue to narrow.

The inverted U-shaped curve of urban-rural gap also reflects the characteristics of China's economic and social development in the same period. In the late 1990s and the beginning of the 21st century, China has experienced rapid industrialization and urbanization, which means that labor, capital, and other production factors have gathered in central cities, and education and medical resources have also been inclined to urban areas. In this way, the difference between urban and rural development levels has been widening. In 2010, China became the second largest economy in the world. In the same year, China's industrialization entered the late stage (Huang, QunHui, Chaoxian Guo, Yanhong Liu, and Wenlong Hu, 2017, Sustainable Industrialization and Innovation Driven. Beijing: Social Science Academic Press. The level of industrialization is comprehensively calculated by five indicators, namely, per capita GDP, urbanization rate, industrial structure, employment proportion of primary industry, and proportion of added value of the manufacturing industry). Environmental pollution and resource constraints gradually emerged. In 2012, when the new government took office, China's economic development concept and model began to adjust. Changing the growth model and promoting the construction of ecological civilization gradually have been written into the development plans and implemented from the central to the local level, which means that the economic development has shifted from focusing on the speed of development to the quality of development; the industrial layout is more 
TABLE 2: Regional classification.

\begin{tabular}{lc}
\hline Region & Included provinces \\
\hline East & Beijing, Tianjin, Hebei, Shanghai, Jiangsu, Zhejiang, Fujian, Shandong, Guangdong, Hainan \\
$\begin{array}{l}\text { Middle } \\
\text { West }\end{array}$ & Shanxi, Anhui, Jiangxi, Henan, Hubei, Hunan \\
Northeast & Chongqing, Sichuan, Guizhou, Yunnan, Shaanxi, Gansu, Qinghai, Ningxia, Xinjiang, Inner Mongolia, Guangxi \\
\hline
\end{tabular}

National Bureau of Statistics, http://www.stats.gov.cn/tjzs/cjwtjd/201308/t20130829_74318.html.

TABLE 3: National Human Development Index by urban and rural areas.

\begin{tabular}{|c|c|c|c|c|c|c|c|c|c|}
\hline \multirow{2}{*}{ Year } & \multicolumn{2}{|c|}{ Education Index } & \multicolumn{2}{|c|}{ Health Index } & \multicolumn{2}{|c|}{ Income Index } & \multicolumn{2}{|c|}{ HDI } & \multirow{2}{*}{ Nationwide } \\
\hline & Urban & Rural & Urban & Rural & Urban & Rural & Urban & Rural & \\
\hline 1995 & 0.556 & 0.403 & 0.817 & 0.746 & 0.538 & 0.406 & 0.625 & 0.496 & 0.548 \\
\hline 1996 & 0.567 & 0.409 & 0.823 & 0.749 & 0.546 & 0.413 & 0.634 & 0.502 & 0.556 \\
\hline 1997 & 0.579 & 0.415 & 0.829 & 0.752 & 0.555 & 0.421 & 0.643 & 0.508 & 0.565 \\
\hline 1998 & 0.577 & 0.419 & 0.837 & 0.755 & 0.563 & 0.428 & 0.648 & 0.514 & 0.574 \\
\hline 1999 & 0.585 & 0.425 & 0.843 & 0.758 & 0.571 & 0.435 & 0.656 & 0.520 & 0.583 \\
\hline 2000 & 0.596 & 0.440 & 0.849 & 0.762 & 0.579 & 0.443 & 0.666 & 0.528 & 0.593 \\
\hline 2001 & 0.615 & 0.450 & 0.853 & 0.766 & 0.591 & 0.449 & 0.677 & 0.537 & 0.599 \\
\hline 2002 & 0.614 & 0.453 & 0.856 & 0.771 & 0.610 & 0.457 & 0.685 & 0.542 & 0.610 \\
\hline 2003 & 0.622 & 0.460 & 0.860 & 0.776 & 0.623 & 0.464 & 0.693 & 0.549 & 0.621 \\
\hline 2004 & 0.629 & 0.467 & 0.864 & 0.781 & 0.634 & 0.475 & 0.701 & 0.557 & 0.634 \\
\hline 2005 & 0.607 & 0.452 & 0.867 & 0.785 & 0.648 & 0.484 & 0.698 & 0.556 & 0.646 \\
\hline 2006 & 0.622 & 0.469 & 0.871 & 0.790 & 0.662 & 0.496 & 0.711 & 0.568 & 0.658 \\
\hline 2007 & 0.627 & 0.479 & 0.874 & 0.795 & 0.679 & 0.510 & 0.720 & 0.579 & 0.673 \\
\hline 2008 & 0.628 & 0.486 & 0.878 & 0.800 & 0.691 & 0.523 & 0.725 & 0.588 & 0.682 \\
\hline 2009 & 0.633 & 0.492 & 0.882 & 0.805 & 0.705 & 0.536 & 0.733 & 0.596 & 0.692 \\
\hline 2010 & 0.666 & 0.505 & 0.885 & 0.809 & 0.716 & 0.552 & 0.750 & 0.609 & 0.701 \\
\hline 2011 & 0.666 & 0.506 & 0.889 & 0.814 & 0.728 & 0.568 & 0.756 & 0.616 & 0.704 \\
\hline 2012 & 0.671 & 0.509 & 0.892 & 0.819 & 0.742 & 0.584 & 0.763 & 0.624 & 0.713 \\
\hline 2013 & 0.677 & 0.514 & 0.896 & 0.824 & 0.752 & 0.597 & 0.770 & 0.632 & 0.723 \\
\hline 2014 & 0.674 & 0.512 & 0.899 & 0.829 & 0.762 & 0.610 & 0.773 & 0.638 & 0.733 \\
\hline 2015 & 0.682 & 0.514 & 0.903 & 0.833 & 0.772 & 0.621 & 0.780 & 0.643 & 0.737 \\
\hline 2016 & 0.679 & 0.513 & 0.907 & 0.838 & 0.780 & 0.630 & 0.783 & 0.647 & 0.748 \\
\hline 2017 & 0.687 & 0.520 & 0.910 & 0.843 & 0.789 & 0.641 & 0.790 & 0.655 & 0.752 \\
\hline
\end{tabular}

The relevant data needed to calculate the 2003 Education Index have statistical errors in the National Statistical Yearbook. Therefore, the 2003 Education Index was obtained by interpolation from the years 2002 and 2004.

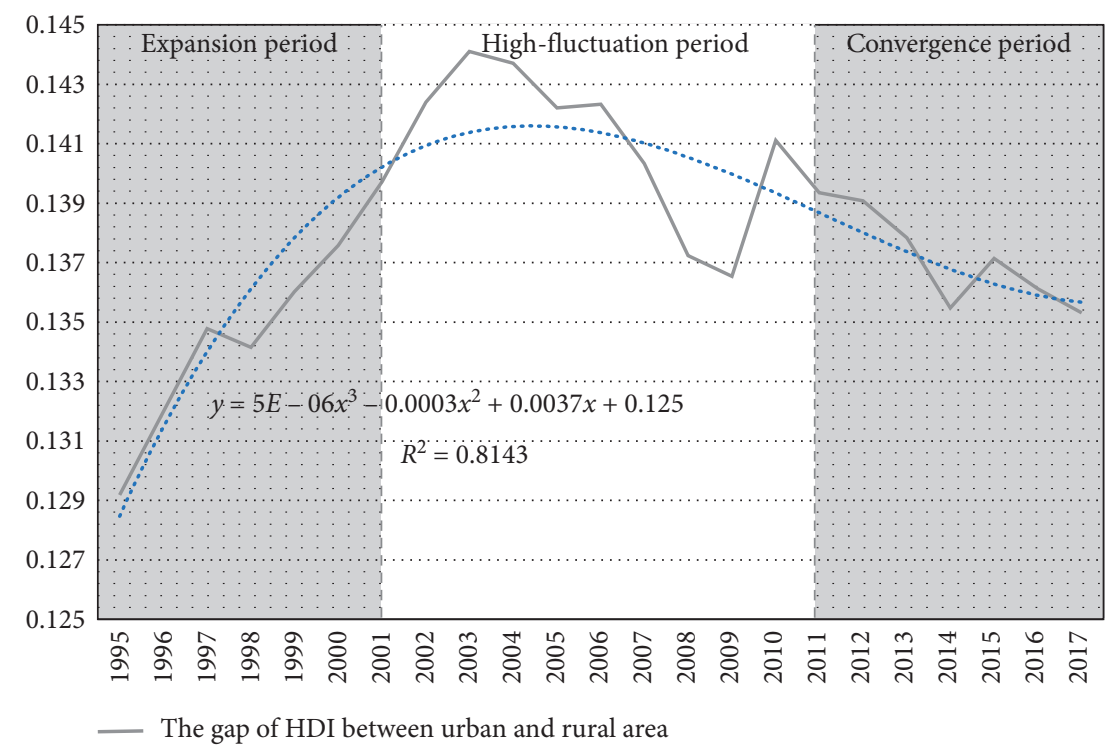

FIgURE 1: Trend map of human development in urban and rural areas in China from 1995 to 2017. Data source: the difference in human development between urban and rural areas comes from the calculation results in this paper. 
TABle 4: Decomposition effects of the differences in urban and rural Human Development Index differences from 1995 to 2017 based on the constituent index.

\begin{tabular}{|c|c|c|c|c|c|c|}
\hline Time period & $\begin{array}{l}\text { Education } \\
\text { index effect }\end{array}$ & $\begin{array}{l}\text { Health index } \\
\text { effect }\end{array}$ & $\begin{array}{c}\text { Income index } \\
\text { effect }\end{array}$ & Total & Narrow gap & Expand gap \\
\hline 1995 2001 & 0.0028 & 0.0047 & 0.0030 & 0.0105 & Income index effect & \\
\hline $\begin{array}{l}\text { (Expansion } \\
\text { period) }\end{array}$ & $(26.45 \%)$ & (44.98\%) & $(28.57 \%)$ & $(100 \%)$ & $\begin{array}{l}\text { Health index effect } \\
\text { Education index effect }\end{array}$ & \\
\hline $2001 \sim 2011$ & -0.0032 & -0.0018 & 0.0047 & -0.0004 & Income index effect & \\
\hline $\begin{array}{l}\text { (High } \\
\text { fluctuation } \\
\text { period) }\end{array}$ & (894.49\%) & (498.24\%) & $(-1292.73 \%)$ & $(100 \%)$ & & $\begin{array}{l}\text { Health index effect } \\
\text { Education index effect }\end{array}$ \\
\hline $2011 \sim 2017$ & 0.0019 & -0.0012 & -0.0047 & -0.0040 & & \\
\hline \multirow[t]{3}{*}{$\begin{array}{l}\text { (Convergence } \\
\text { period) }\end{array}$} & $(-46.22 \%)$ & $(29.00 \%)$ & (117.22\%) & $(100 \%)$ & & Health index effect \\
\hline & & & & & Education index effect & \\
\hline & & & & & $\begin{array}{llll}-0.006 & -0.004 & -0.002\end{array}$ & $\begin{array}{ccc}0.002 & 0.004 & 0.006\end{array}$ \\
\hline
\end{tabular}

Note: The numbers in brackets in Table 4 are the contribution rates of the corresponding constituent indexes.

balanced, and green and low-carbon development has become the mainstream. In 2014, the new urbanization plan clearly put forward a series of measures, such as local urbanization, equalization of urban and rural public services, and reform and innovation of the household registration system, to promote urban-rural balance and integrated development. Targeted poverty alleviation strategy and "Healthy China 2030" planning outline are also widely implemented in rural areas. These policies and measures are carried out in coordination to promote the continuous narrowing of the gap between urban and rural development levels.

3.2. Factors Affecting Decomposition of the Differences in Urban and Rural Human Development. According to formula (4), changes in the gap between rural and urban development in China can be decomposed into changes based on three index effects: Health Index, Income Index, and Education Index. If the effect value is positive, it indicates that the index is promoting the expansion of the urban-rural gap; if the effect value is negative, it indicates that the index has contributed to reducing the urban-rural gap. From the comparison of the constituent index effects at different time periods, the expansion of urban-rural disparities in 1995-2001 was the result of the joint promotion of Education Index, Medical Index, and Income Index. The urbanrural gaps in these three fields are expanding and driving the overall urban-rural gap with the Health Index being the largest driving effect which has a decomposition effect value of 0.0047 , followed by the Income Index of 0.0030 , and the minimum Education Index of 0.0028. During the high fluctuation period of the urban-rural gap from 2001 to 2011, the rapid growth of the urban-rural gap was controlled, mainly due to the decline in the urban-rural education gap and life expectancy gap. Although the income gap was increasing, this increase was less than the decline in the health gap and Education Index gap; during the convergence period between 2011 and 2017, the gap between urban and rural areas showed a relatively stable decline, mainly due to the sharp decline in the urban-rural income gap. The education gap expanded during the period, but the expansion was smaller than the reduction in the urban-rural income gap and health gap. In the future, in order to maintain a steady trend of continuous decline of the gap between the urban and rural areas, the declining trend of income and Health Index differences between urban and rural areas needs to be continued, the widening education gap needs to be converted, and the Education Index needs to be made a positive factor in narrowing the gap of the Human Development Index between urban and rural areas (Table 4).

3.3. Analysis of the Spatial Equilibrium of the Difference between Urban and Rural Human Development. According to formula (5), the smaller the coefficient of variation, the better the spatial equilibrium of the urban and rural Human Development Index gap (Figure 2). Conversely, the larger the coefficient of variation, the lower the equilibrium of the urban and rural Human Development Index gap in the region. The calculation results show that the country's overall coefficient of variation is declining, from 0.24 in 1995 to 0.18 in 2017, with an average annual decrease of 0.66 . The trends for three regions out of the four regions of east, middle, west, and northeast are the same with the overall trend across the country. The west fell from 0.35 in 1995 to 0.25 in 2017, a drop of 0.1 ; the northeast fell from 0.20 to 0.07 , a drop of 0.13 ; the east dropped from 0.18 to 0.12 , a 


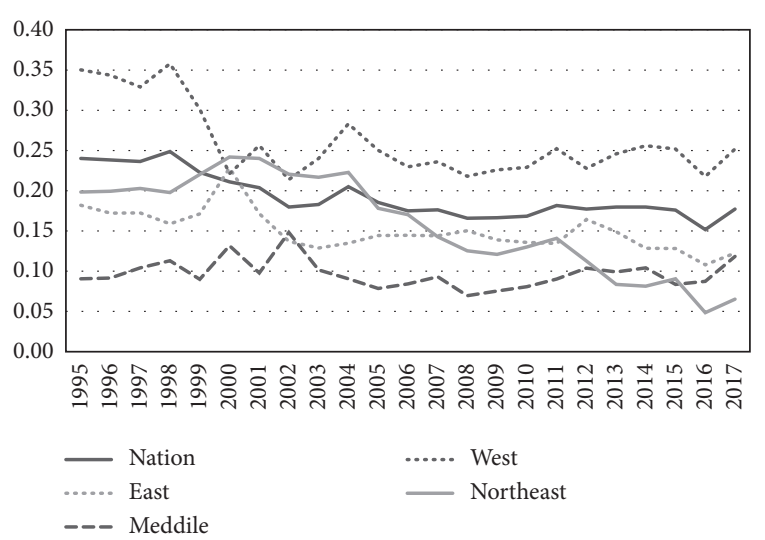

Figure 2: Variation coefficients of human development gaps between urban and rural areas in China, 1995-2017. Data source: the coefficient of variation is from the calculation results in this paper.

drop of 0.06 . The coefficient of variation in the middle increased slightly from 1995 to 2017 , from 0.09 to 0.12 .

From the change characteristics of the four regional coefficients of variation, the value of the coefficient of variation in the west is significantly higher than that in the country and the three regions in the east, middle, and northeast. Although the coefficient of variation of the western region has decreased significantly compared to 1995 , the coefficient of variation in the west is still significantly larger than that of the country and the other three regions. The northeast has become the region with the largest decrease in the coefficient of variation since 1995-2007, with a decrease of 0.13 , which is higher than 0.1 in the west and 0.06 in the east. Which is also higher than the country's overall 0.06 . Although the coefficient of variation of the middle region showed an upward trend from 1995 to 2017, because the value of the coefficient of variation has always been at a low level, the increase was generally small, and its equilibrium was relatively good in the four regions. Therefore, from the variation characteristics of the four regional coefficients of variation, the equilibrium of the gap between the urban and rural Human Development Index is relatively good in the middle and northeastern provinces, followed by the east, and there is still much room for improvement in the balance of the west.

\section{Conclusion and Policy Implications}

Based on the 1995-2017 national time series data, the panel data of each province and the adjusted Human Development Index calculation method of the United Nations Development Program, the urban and rural Human Development Index of China were calculated. Using the method of Logarithmic Mean Weight Divisia, this paper decomposes the dynamic changes of the urban and rural Human Development Index and analyzes the spatial equilibrium change characteristics of urban and rural Human Development Index. The main conclusions are as follows:

(1) Based on the time series analysis of the urban-rural HDI, this paper firstly proposes an "inverted U" curve for the difference of human development level between urban and rural China, which shows that the gap of human development levels between urban and rural China has undergone a process from expansion to high fluctuations to continuous convergence; this "inverted U" curve can be divided into three periods as time develops: the expansion period (1995-2001), the high-fluctuation period (2001-2011), and the convergence period (2011-2017).

(2) Judging from the decomposition effect of the gap between the urban and rural human development levels across the country, the gap expansion period is caused by the joint promotion of the Health Index, Education Index, and Income Index; the gap between urban and rural areas has been narrowed in the high-fluctuation period; the convergence period is reflected in the overall decline in the gap between urban and rural areas, mainly due to the decline in the Income Index and the Health Index. The Education Index has become a factor that widens the gap, but due to the large decline in the Income and Health Index, the period as a whole shows a trend of narrowing the gap.

(3) From the perspective of the spatial evolution characteristics of the gap between urban and rural human development, the overall coefficient of variation of the country shows a downward trend, and the degree of spatial equilibrium is gradually increasing. The overall change trends in the east, west, and northeast of the country are the same, showing a downward trend. The decline is the greatest in the northeast, followed by the west, and the least in the east; the middle shows a slight upward trend, but its values in each year have been smaller compared to other regions. Generally speaking, the gap between urban and rural human development levels is relatively good in the middle and northeast, followed by the east, and there is still much room for improvement in the balance of the west.

Based on the above conclusions, this paper proposes the following suggestions on how to further narrow the gap between urban and rural areas: first, based on the "inverted U" curve of the gap between urban and rural human development levels proposed in this paper, it shows that China's urban-rural gap and coordinated urban-rural development have entered a new stage. Further research is needed to identify the main problems, difficulties, action ideas, and paths to reduce the gap between urban and rural areas in the new stage and new period, and provide a theoretical research basis for solving the imbalance between urban and rural development and promoting the development of urban-rural integration; second, the research in this paper shows that since 2011, the gap between the urban and rural Human Development Index in China has shown a general trend of convergence. The narrowing of the gap in income and health development is the main reason for the narrowing of the gap between urban and rural areas. The 
imbalance in the development of urban and rural education needs attention. The evaluation of the adequacy, the intensity, and effectiveness of the implementation of the formulation of urban-rural balanced education policies is conducted, key issues are identified, and implementation solutions are explored. Third, from the perspective of the regional equilibrium of the gap between urban and rural human development, the balance of the west is still significantly lower than other regions. It is necessary to continue to vigorously promote and implement policies and measures to promote economic and social development in the western region. Through efficient implementation of policies and the provision of accurate assistance to the western region, we can promote the improvement of the overall development level of the western region and reduce the gap between urban and rural development, achieve the overall balanced development of the western region, and also promote the overall balanced urban and rural development of the whole country.

Limited by the availability of data, the accuracy of some indicators in this study can be improved. Due to the lack of long time series of urban and rural life expectancy data statistic in China, the Health Index can only be calculated by the interpolation method, and showing a general trend of change, hopefully, annual statistics will be available in the future. As to further study next step, the team wish to check the data availability of other countries and carry out international comparison to explore the change law of the Human Development Index based on the studies of various kinds of countries including developed and developing countries, so that the study can better guide and serve the balanced economic and social development of developing countries.

\section{Data Availability}

The "proportion of primary, junior, high, and university and above school population by urban and rural areas in nation and provinces" data are available from the "China Statistical Yearbook (1996-2018)” (http://data.cnki.net/Yearbook/ Navi?type=type \& code=A). The "per capita US dollar GNI measured in purchasing power parity (PPP) in 2011 by urban and rural areas in nation and provinces" data are available from the "China Statistical Yearbook (1996-2018)" and "World Bank Open Data" (1)http://data.cnki.net/ Yearbook/Navi?type=type \& code=A; (2)https://data. worldbank.org.cn/indicator/NY.GNP.PCAP.PP.KD?

locations $=\mathrm{CN}$ ). The "life expectancy by urban and rural areas in nation" data are available from the public domain resources (1) http://kns.cnki.net/kcms/detail/detail.aspx? FileName=JJYJ200411000 \& DbName=CJFQ2004; (2) http://kns.cnki.net/kcms/detail/detail.aspx?

FileName=SCRK201002011 \& DbName=CJFQ2010). The "life expectancy by urban and rural areas in provinces" data are available from the corresponding author upon request. The "Human Development Index related indicators for maximum and minimum criteria," "Education Index, Health Index, Income Index, and Human Development Index by urban and rural areas in China," "decomposition effects of the differences in urban and rural Human
Development Index," and "variation coefficients of human development gaps between urban and rural areas in country and regions" data are included within the article. The "per capita disposable income of urban and rural residents in China" data are available from the "China Statistical Yearbook (2018)" (http://www.stats.gov.cn/tjsj/ndsj/2018/ indexch.htm).

\section{Conflicts of Interest}

There are no conflicts of interest to declare.

\section{Acknowledgments}

This paper received valuable comments and suggestions from Prof. Pan Jiahua, the academician of the Chinese Academy of Social Sciences, and professor Yang Jun of China Northeastern University. This study was supported by the China National Social Science Foundation (grant no. 16AGJ011) and CASS Thinktank for Eco-Civilization Studies (grant no. STWM-2019-C).

\section{References}

[1] D. Wang and Y. P. He, "The essence, multifacetedness and policy implication of the urban-rural gap," China Rural Watch, vol. 3, pp. 25-80, 2005.

[2] W. Guo, "The performance, reasons and policy adjustment of the widening urban-rural gap," Agricultural Economic Issues, no. 5, pp. 10-79, 2003.

[3] C. Y. Zhong, B. M. Li, and J. H. Wang, "Urban-rural gap and overall urban-rural development approach," Economic Geography, vol. 6, pp. 936-938, 2007.

[4] Y. Cai and T. Yang, "Political economics of urban-rural income gap," Chinese Social Sciences, vol. 4, pp. 11-22, 2000.

[5] J. P. Guo, "Urban-rural integration: the fundamental way out to solve the "three rural" issues," Theoretical Exploration, vol. 1, pp. 57-59, 2004.

[6] J. P. Guo, "The manifestation, reasons and institutional innovation of the widening gap between urban and rural areas," Journal of Huazhong Agricultural University (Social Science Edition), vol. 3, pp. 8-11, 2004.

[7] W. Liu, "Eight problems to be faced in urbanization development," Economist, vol. 1, pp. 77-85, 2006.

[8] M. K. Wang, "Two major problems in China's modernization process: urban-rural gap and regional disparity," Agricultural Economic Issues, no. 5, pp. 4-12, 2004.

[9] F. Y. Hou and F. B. Zhang, "A look at the urban-rural gap in China's dual economy from the perspective of human capital," Journal of Shandong University (Philosophy and Social Sciences), vol. 4, pp. 133-138, 2006.

[10] W. Zhao, "The urban-rural gap in China: rethinking the causes and adjusting policies," Journal of Wuhan University (Philosophy and Social Sciences Edition), vol. 6, pp. 742-748, 2004.

[11] D. N. Cheng, "On urban bias and rural poverty," Journal of Wuhan University (Philosophy and Social Sciences Edition), vol. 2, pp. 255-260, 2005.

[12] H. Y. Song and Y. L. Ma, "An estimation of the urban-rural gap in China using the Human Development Index," Economic Research, vol. 11, pp. 4-15, 2004. 
[13] UNDP and Government of Mongolia, "Human development index report Mongolia 2003,” 2003, http://hdr.undp.org/sites/ default/files/mongolia_2003_en.pdf.

[14] G. C. Nandi, "Human development in Assam: a study of ruralurban disparity," 2010, https://www.academia.edu/10397445/ Human_development_in_Assam_A_study_of_Rural_-_Urban_ Disparity.

[15] World Bank, "LAC equity lab: income inequality-urban/rural inequality," 2019, https://www.worldbank.org/en/topic/poverty/ lac-equity-lab1/income-inequality/urban-rural-inequality.

[16] C. L. Li, "The changing trend of educational inequality in China (1940-2010): reexamining the urban-rural gap on educational opportunity," Sociological Studies, vol. 29, no. 2, pp. 65-89, 2014.

[17] D. L. Su, "The present situation, reasons and countermeasures of the income gap between urban and rural areas in China," in Proceedings of 2018 International Symposium on Social Science and Management Innovation (SSMI 2018), pp. 394-398, Xi'an, China, December 2018.

[18] G. X. Li, "Convergence of income gap between new urbanization urban and rural residents-T-test method based on paired data," Journal of Guizhou University of Finance and Economics, vol. 5, pp. 96-103, 2018.

[19] Y. H. Cheng, "Evolution of the national Gini coefficient and its urban-rural decomposition since the reform," Chinese Social Sciences, vol. 4, pp. 45-60, 2007.

[20] X. H. Li and F. R. Wang, "Dynamic prediction of the gap between urban and rural residents' consumption level," Research on Business Economy, vol. 13, pp. 41-44, 2018.

[21] C. Wang, G. Wan, and D. Yang, "Income inequality in the people's Republic of China: trends, determinants, and proposed remedies," Journal of Economic Surveys, vol. 28, no. 4, pp. 686-708, 2014.

[22] H. Viktoria and A. Lahiri, "Urbanization, structural transformation and rural urban disparities in China and India," 2018, https://faculty.arts.ubc.ca/vhnatkovska/Research/China India_urban_Modelappendix.pdf.

[23] C. R. Chen and T. J. Zhi, "The trend and trend of balanced development of basic education informatization in China," Education Research, vol. 39, no. 8, pp. 129-140, 2018.

[24] F. Gao, "Connotation transformation of China's urban-rural gap and its political economics interpretation in the new era," Journal of Northwest University (Philosophy and Social Science Edition), vol. 48, no. 4, pp. 5-16, 2018.

[25] C. Binkai and Y. F. Lin, "Development strategy, urbanization and the urban-rural income gap in China," Social Sciences in China, vol. 35, no. 1, pp. 5-20, 2014.

[26] C. L. Luo, "Income composition and inequality in China," Journal of Beijing Technology and Business University (Social Sciences), vol. 35, no. 4, pp. 32-42, 2020.

[27] A. P. He and Q. H. Li, "Historical changes and future prospects of income gap between urban and rural residents in China in the past 70 years since the founding of new China," Economic Review Journal, vol. 10, pp. 16-23, 2019.

[28] C. D. Gu, F. L. Wang, and F. Luo, "Difference in and determinants of subjective well-being for Chinese urban and rural residents," World Regional Studies, pp. 1-14, 2020.

[29] Y. X. Huang, "Constructing the thinking frame and policy system of rural revitalization," Research on Financial and Economic Issues, pp. 1-5, 2020.

[30] F. Shi, J. Zhang, and C. Wang, "Spatial differences and influencing factors of entrepreneurial intention of urban and rural residents in China," Geographical Research, vol. 39, no. 8, pp. 1852-1863, 2020.
[31] J. G. Pang, "China's consumption structure upgrading: realistic dynamic analysis and trend research," Journal of Commercial Economics, vol. 14, pp. 62-65, 2020.

[32] P. P. Song and H. Sun, "Upgrading and convergence: an analysis of consumption structure of urban and rural residents from the perspective of demand intensity," Agricultural Economy, vol. 8, pp. 79-80, 2020.

[33] G. Y. Sheng, "Research on the difference and improvement of infrastructure and public service between Chinas urban and rural area," Regional Economic Review, vol. 4, pp. 52-59, 2020.

[34] W. H. Li, "Urban-rural and regional gaps in resident income and institutional innovation," Economic Geography, vol. 39, no. 3, pp. 195-200, 2019.

[35] X. H. Zong, S. H. Yang, and S. Y. Qin, “Aspiring for education with fairness and quality: factors affecting the urban-rural quality gap of compulsory education and balancing strategies in the new era," Tsinghua Journal of Education, vol. 39, no. 6, pp. 47-57, 2018.

[36] M. L. Xia and J. H. Sun, "An empirical study on the gap of education cost between preschools in urban and rural areas in China and suggestions for policy making," Contemporary Education and Culture, vol. 11, no. 1, pp. 108-114, 2019.

[37] Z. X. Tan, "A comparative study on the property income of urban and rural residents in the process of Urbanization-a neglected gap," Study \& Exploration, vol. 1, pp. 131-137, 2020.

[38] X. M. Gao and J. X. Guo, "International experience and enlightenment of urban and rural economic structural transformation," Economic Review Journal, vol. 1, pp. 123$132,2020$.

[39] E. T. Jin, S. Y. Wang, J. Jiang, and K. Q. Zheng, "Regional difference and policy analysis of the urban-rural well-being gap in China in the 21st century," Journal of Public Administration, vol. 12, no. 4, pp. 143-160, 2019.

[40] D. Li and Y. Pei, "A research on the impact of urban-rural public service gap on urban-rural income gap," Journal of Finance and Economics, vol. 45, no. 4, pp. 111-123, 2019.

[41] X. Qi and L. Zheng, "An empirical study on the academic gap between urban and rural areas and its influencing factors," Journal of the Chinese Society of Education, vol. 3, pp. 36-39, 2019.

[42] J. Z. Zhang, Y. X. Zhu, and X. Z. Zhu, "The characteristic and tendency of per capita annual income between urban and rural households in China," Chinese Journal of Agricultural Resources and Regional Planning, vol. 39, no. 12, pp. 237-243, 2018.

[43] S. Zhu, C. Yu, and C. He, "Export structures, income inequality and urban-rural divide in China," Applied Geography, vol. 115, p. 102150, 2020.

[44] H. F. Shen and P. Mao, "The empirical study on the urbanrural income gap in China," International Journal of Business and Social Science, vol. 9, no. 1, pp. 115-122, 2018.

[45] J. W. Gan, "Impacts of urban-rural income gap on consumer demand in China," in Proceedings of the 3rd International Symposium On Asian B\&R Conference On International Business Cooperation (ISBCD 2018), Kunming, China, October 2018.

[46] Y. Hu, "Analysis of the average life expectancy of the urban and rural population in China," Population and Development, vol. 16, no. 2, pp. 41-47, 2010. 